\title{
Action of Uncouplers of Oxidative Phosphorylation as Chemotactic Repellents of Bacillus subtilis
}

\author{
By GEORGE W. ORDAL* AND DAVID P. VILLANI \\ School of Basic Medical Sciences and Department of Biochemistry, 190 Medical \\ Sciences Building, University of Illinois, Urbana, Illinois 61801, U.S.A.
}

(Received 26 September 1979; revised 12 December 1979)

\begin{abstract}
Bacillus subtilis alternately swims smoothly and tumbles; when administered repellent it only tumbles, but later resumes normal swimming and tumbling. Repellents of $B$. subtilis include membrane-active agents like uncouplers of oxidative phosphorylation and local anaesthetics and have previously been found to act in a fundamentally different way compared with attractants. It has been suggested previously that uncouplers act as repellents as a result of their ability to depolarize the membrane and that depolarization might affect flagellar function by causing a flux of $\mathrm{Ca}^{2+}$ into the cell. However, we found that there is no correlation between membrane depolarization and chemotaxis and no detectable flux of $\mathrm{Ca}^{2+}$ following tactic stimulation by uncouplers. Experiments with analogues of the uncoupler pentachlorophenol, all of which are weaker acids than pentachlorophenol, indicated that the anionic form of the uncoupler is the potent form and we propose that it binds to a certain membrane protein to cause release into the cytoplasm of the substance (ion, metabolite or protein) that controls tumbling frequency. Adaptation is assumed to occur when this excess is removed by active transport or metabolism.
\end{abstract}

\section{INTRODUCTION}

Chemotaxis is the process by which bacteria travel to higher concentrations of attractant or lower concentrations of repellent. It has attracted wide interest as the antecedent of the multiplicity of sensory-motor processes in nature. Peritrichous bacteria like Escherichia coli, Salmonella typhimurium and Bacillus subtilis alternately swim smoothly and tumble (Berg \& Brown, 1972). Tumbling is a chaotic motion which randomly reorients the bacterium for the next swim. Chemotaxis occurs because bacteria swim for longer periods when headed in the favourable direction and shorter periods when headed in the unfavourable direction, compared with the duration of swim in an isotropic medium. Indeed, addition of attractant or removal of repellent causes a transient period of completely smooth swimming and removal of attractant or addition of repellent causes a transient period of tumbling (Macnab \& Koshland, 1972; Ordal \& Goldman, 1975; Tsang et al., 1973). Attractants act by binding, without the need for transport, at specific chemoreceptors (Adler, 1969; Aksamit \& Koshland, 1974; Hazelbauer \& Adler, 1971; Ordal et al., 1978).

There are many reasons for believing that repellents of $B$. subtilis, such as uncouplers of oxidative phosphorylation, affect behaviour by a fundamentally different mechanism from attractants or from repellents in enteric bacteria (Ordal 1976a; Ordal \& Goldman, 1975, 1976; Tsang et al., 1973; Tso \& Adler, 1974). Ordal \& Goldman (1976) proposed that they act directly on the membrane to cause tumbling rather than through orthodox chemoreceptors. The means by which they act on the membrane is not clear but, based on the known effects of uncouplers on bacterial, mitochondrial and artificial membranes, as interpreted by the chemiosmotic hypothesis (Mitchell, 1966), Ordal \& Goldman (1975, 
1976) postulated that uncouplers of oxidative phosphorylation bring about tumbling by causing a depolarization of the plasma membrane. Miller \& Koshland (1977) presented evidence that in $B$. subtilis the uncoupler carbonyl cyanide $m$-chlorophenylhydrazone (CCCP) does indeed produce a transient, albeit long-lived, depolarization of the membrane. In these experiments, they found that a cyanine dye, 3,3'-dipropylthiodicarbocyanine iodide, shows increased fluorescence and the lipophilic cation triphenylmethylphosphonium ion is lost from the cell as a consequence of adding CCCP.

A possible clue to the molecular mechanism by which repellents of $B$. subtilis might bring about a period of transient tumbling was the observation that whether a bacterium swims or tumbles depends on the cytoplasmic concentration of free $\mathrm{Ca}^{2+}$, low concentrations favouring swimming and high concentrations favouring tumbling (Ordal, 1977). Pentachlorophenol, an uncoupler of oxidative phosphorylation, causes $B$. subtilis to tumble only when the external $\mathrm{Ca}^{2+}$ concentration is $0.1 \mu \mathrm{M}$ or higher. Accordingly, Ordal (1977) and Ordal \& Fields (1977) postulated that uncouplers bring about tumbling by catalysing a transient depolarization of the plasma membrane during which time $\mathrm{Ca}^{2+}$ enters the cell. Afterwards, $\mathrm{Ca}^{2+}$ is removed by active transport (Rosen \& McClees, 1974), and when the concentration has finally returned to normal, the bacteria resume normal swimming and tumbling. However, Ordal (1976b) found that uncouplers interact at specific sites to cause tumbling and that chemically dissimilar membrane-active agents - including such different uncouplers as carbonyl cyanide trifluoromethoxyphenylhydrazone, pentachlorophenol and $3,3^{\prime}, 4^{\prime} 5$-tetrachlorosalicylanilide, as well as other compounds like tetracaine (a local anaesthetic), chloropromazine (a central nervous system depressant), tetraphenylboron (a permeant anion of a strong acid) and cyanide - act at different sites. This finding led to the supposition that uncouplers and other agents may exert their effects on biological processes through specific interaction and prompted a series of experiments in which Brummett \& Ordal (1977) and Nicholas \& Ordal (1978) showed that uncouplers inhibit amino acid transport in $B$. subtilis by specific interaction, probably as an anion, with the respective transport proteins themselves, rather than by draining away the energy supplies of the cell by membrane depolarization.

In the present study we have sought to evaluate whether membrane depolarization or flux of $\mathrm{Ca}^{2+}$ plays a significant role in negative chemotaxis in $B$. subtilis and whether it is the anionic form of the chlorinated phenols that has repellent activity.

\section{METHODS}

Abbreviations. CCCP, Carbonyl cyanide $m$-chlorophenylhydrazone; FCCP, carbonyl cyanide trifluoromethoxyphenylhydrazone; PCP, pentachlorophenol; 3,4,5-TCP, 3,4,5-trichlorophenol; 2,4,6-TCP, 2,4,6trichlorophenol; 3,5-DCP, 3,5-dichlorophenol; TCSA, 3,3',4'5-tetrachlorosalicylanilide; TPB-, tetraphenylboron.

Strains. Bacillus subtilis strain OI 8 (ilvCI leu-I) has been described (Ordal \& Goldman, 1975). Strain OI 1085 was derived from 018 (Ullah \& Ordal, unpublished results) and has the markers hisB (amber) trpF7 (amber) met. Strain OI 1100 was derived from OI 1085 (Ullah \& Ordal, unpublished results) and is a chemotaxis mutant whose methyl-accepting chemotaxis proteins (MCPs; Kort et al., 1975) are believed not to be subject to normal methylation/demethylation.

Chemicals. ${ }^{45} \mathrm{CaCl}_{2}$ was obtained from New England Nuclear Corp. FCCP was a gift from Dr P. G. Heytler, E. 1. duPont de Nemours \& Co., Wilmington, Delaware, U.S.A. All other chemicals were obtained from commercial sources. 3,4,5-TCP and 3,5-DCP were further purified by sublimation. 2,4,6-TCP was purified by recrystallization.

Media. Minimal medium for growth and tryptone broth with added divalent cations were as described by Ordal \& Goldman (1975). Medium for ${ }^{45} \mathrm{Ca}^{2+}$ flux experiments contained $10 \mathrm{mM}$-Tris $\mathrm{pH} 7 \cdot 5,0 \cdot 2 \mu \mathrm{M}-$ EDTA, 2.5 mm-glycerol, $2.5 \mathrm{~mm}$-sodium lactate, $0.15 \mathrm{~mm}^{-}\left(\mathrm{NH}_{4}\right)_{2} \mathrm{SO}_{4}$ and $50 \mathrm{~mm}-\mathrm{KSCN}$. Wash buffer was the same except that 1 mM-EGTA was added. Chemotaxis buffer was as described by Ordal \& Goldman (1975). For behavioural experiments, glycerol was omitted. Cyanine dye medium contained $0 \cdot 1 \mathrm{M}-\mathrm{KCl}$ (or KSCN), 3.16 $\mu \mathrm{M}$-EDTA, $0 \cdot 1 \mathrm{~mm}$-sodium lactate and $0 \cdot 1 \mathrm{~mm}-\mathrm{CaCl}_{2}$. 
${ }^{45} \mathrm{Ca}^{2+}$ flux experiments. Strain OI 8 was inoculated from spores into tryptone broth for overnight growth. The culture was diluted 1:50 into minimal medium with $20 \mathrm{~mm}$-glycerol and lactate to an $A_{600}$ of 0.5 unit, washed twice and suspended in $8.5 \mathrm{ml}$ medium at an $A_{600}$ of 0.6 unit. Bacteria were incubated at $30^{\circ} \mathrm{C}$ with bubbling and supplemented with $0.6 \mu \mathrm{M}^{-45} \mathrm{Ca}^{2}+\left(18.34 \mathrm{mCi} \mathrm{mg}^{-1}, 678 \mathrm{MBq} \mathrm{mg}^{-1}\right)$. Other reagents were added at the times indicated in the legend to Fig. 1. At appropriate times, $1 \mathrm{ml}$ samples were withdrawn using a Finnpipette, filtered and washed twice with wash buffer. Filters were dried and counted for radioactivity. The $95 \%$ confidence limits for variation of sampling on these experiments were found to be about $34 \%$. Assuming the internal volume of $B$. subtilis is $2 \mathrm{ml}$ ( $\mathrm{g}$ dry wt) ${ }^{-1}$ (Miller \& Koshland, 1977), the internal total $\mathrm{Ca}^{2+}$ content was about $0 \cdot 2$ to $0 \cdot 3 \mu \mathrm{M}$.

Membrane potential experiments. The method of Miller \& Koshland (1977) was followed. Strain OI 8 was grown in tryptone broth with added divalent cations to an $A_{600}$ of between 0.6 and 1 unit, filtered, washed with cyanine dye medium (except where noted) and suspended in the medium at an $A_{600}$ of 0.38 unit. Cyanine dye (3,3'-dipropylthiodicarbocyanine iodide) was added in $95 \%$ ethanol to a final concentration of $0.77 \mu \mathrm{M}$ in a total volume of $1.3 \mathrm{ml}$ for the experiments reported here. Fluorescence measurements were made on a continuously stirred suspension in a Perkin-Elmer MPF-3 fluorimeter using excitation at $622 \mathrm{~nm}$ and emission at $670 \mathrm{~nm}$ with band widths of $10 \mathrm{~nm}$. Reagents were added by injection with disposable micropipettes. An increase in fluorescence indicated depolarization of the plasma membrane. After each measurement, cuvettes were washed with acid-based detergent and exhaustively rinsed.

Chemotaxis assays. The procedure of Ordal (1976c) was generally followed. Bacteria were grown in nutrient broth with added divalent cations (Ordal \& Goldman, 1975) to an $A_{600}$ of 1.5 to 1.8 units, filtered, washed and suspended in chemotaxis buffer without lactate. For the chemotaxis experiments reported in Results under Membrane depolarization, bacteria were grown and treated in the same way as for measurements of membrane potential but were analysed for chemotaxis instead. Control experiments showed that the presence of cyanine dye did not affect the threshold concentration for FCCP. In general, $9 \mu 1$ drops were placed on an acid-washed microscope slide and, in blind experiments, reagent or buffer was squirted into the suspension after $30 \mathrm{~s}$ and observations made within seconds. The threshold concentration was defined as the lowest concentration that reproducibly caused tumbling (compared with the buffer control).

\section{RESULTS}

\section{Fluxes of $\mathrm{Ca}^{2+}$}

To test whether fluxes of $\mathrm{Ca}^{2+}$ accompanied addition of repellent to B. subtilis, the bacteria were incubated in $0.6 \mu \mathrm{M}^{-}{ }^{45} \mathrm{CaCl}_{2}$ until a steady state was reached and then repellent was added. Fairly high concentrations of FCCP, an uncoupler, or tetracaine, a local anaesthetic, did not bring about influx, then efflux, of $\mathrm{Ca}^{2+}$ (Fig. 1). Even higher concentrations, which made the bacteria non-motile, brought about a gradual influx of $\mathrm{Ca}^{2+}$ (results not shown). However, as postulated by Ordal (1977), addition of ionophore A23187 did cause influx of $\mathrm{Ca}^{2+}$ (Fig. 1).

\section{Membrane depolarization}

Both FCCP and PCP (Fig. 2) caused a transient depolarization of the plasma membrane, as measured by cyanine dye according to the procedure of Miller \& Koshland (1977). Valinomycin, added to bacteria in $0.1 \mathrm{M}-\mathrm{KCl}$, also depolarized the membrane (results not shown), although here there was very little recovery. These observations confirm those of Miller \& Koshland (1977).

Several lines of evidence suggest that the fluorescence changes induced by FCCP do not have any relation to chemotaxis. (i) Substitution of $0 \cdot 1 \mathrm{M}-\mathrm{KSCN}$ for $0 \cdot 1 \mathrm{M}-\mathrm{KCl}$ nearly abolished fluorescence increase due to the addition of $0.23 \mu \mathrm{M}$-FCCP (Fig. $2 b$ ) but changed the chemotaxis threshold only slightly (from 18 to $32 \mathrm{~nm}$-FCCP). (ii) When the chemotaxis buffer of Ordal \& Goldman (1975) was used instead, $0.23 \mu \mathrm{M}-\mathrm{FCCP}$ had almost no effect (Fig. $2 c$ ), although $0.77 \mu \mathrm{M}$-FCCP did cause some depolarization; yet the threshold in this buffer was only slightly increased (from 18 to $32 \mathrm{~nm}$ ). (iii) Addition of $77 \mathrm{nM}-\mathrm{FCCP}$ only produced 0.25 unit of fluorescence increase, with little recovery ( 1 unit of fluorescence is defined as the distance from the baseline to the fluorescence of cells with dye before the addition of reagent). Further addition of $77 \mathrm{nM}-\mathrm{FCCP}$ raised the fluorescence to 0.82 unit 




Fig. 1. Effect of reagents on cytoplasmic calcium. Bacteria were prepared and treated as described in Methods. Just after the sample was taken at $10 \mathrm{~min}$, reagent in $95 \%(\mathrm{v} / \mathrm{v})$ ethanol, or ethanol as control, was added such that the final concentration of ethanol was not more than $0.35 \%$. The concentrations of repellents used were very high, just below those making the bacteria non-motile, to maximize the chance of observing the possible influx, followed by efflux, of $\mathrm{Ca}^{2+}$. FCCP; $\bigcirc, 0.53$ mM-tetracaine; $\square, 5 \mu \mathrm{M}-\mathrm{A} 23187 ; \Delta$, control (ethanol).

with subsequent recovery to 0.4 unit (Fig. $2 d$ ). Thus, small amounts of FCCP sensitized the bacteria to further addition of small amounts. By contrast, this amount of FCCP greatly desensitized the bacteria to tumbling caused by addition of further FCCP. Ordal (1976b) has shown that tumbling is caused by interaction of FCCP with a binding site, with an estimated dissociation constant of $60 \mathrm{nM}$. At $77 \mathrm{nM}, 56 \%$ of this protein would become titrated and at $150 \mathrm{~nm}$, an additional $15 \%$. (At least $13.5 \%$ of this protein has to become titrated to cause tumbling: titration of more than this increases the duration of tumbling.) (iv) Likewise, addition of $0.77 \mu \mathrm{M}$-PCP sensitized bacteria to the addition of $77 \mathrm{nM}$-FCCP but had no effect on the chemotaxis threshold. (v) Tetracaine did not cause depolarization as measured by cyanine dye (results not shown). Therefore, although the fluorescence increase due to addition of uncouplers is interesting in its own right, it does not appear to be connected with chemotaxis. Both are independent consequences of the interaction of uncoupler with bacteria.

\section{Chemotaxis}

In an effort to understand the mechanism by which repellent uncouplers bring about transient tumbling, the threshold concentrations of several repellents were determined as a function of $\mathrm{pH}$. These experiments were patterned on those of Nicholas \& Ordal (1978) in which analogues of PCP were tested for their ability to inhibit amino acid transport. The more highly substituted chlorophenols, which are stronger acids, were more potent inhibitors; thus, the anion was the inhibiting species. The loci of inhibition were considered to be within the membrane.

As with the inhibition of amino acid transport, the more highly substituted chlorophenols were the more potent repellents (Table 1). As argued in the Discussion, the binding sites for causing tumbling lie within the membrane. Nicholas \& Ordal (1978) measured partition coefficients between water and carbon tetrachloride, whose dielectric constant of 2.238 is similar to that of the hydrocarbon phase of the membrane, to determine the concentrations of free chlorophenol within the membrane that correspond to respective aqueous concentra- 


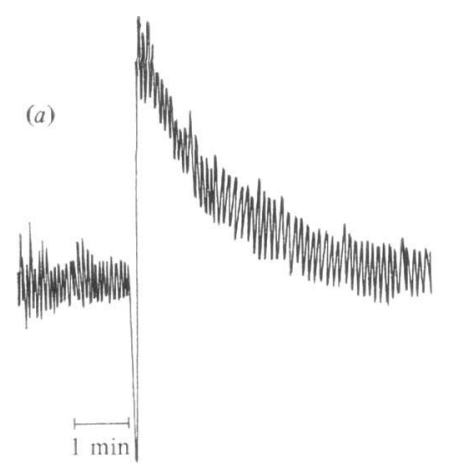

(b)
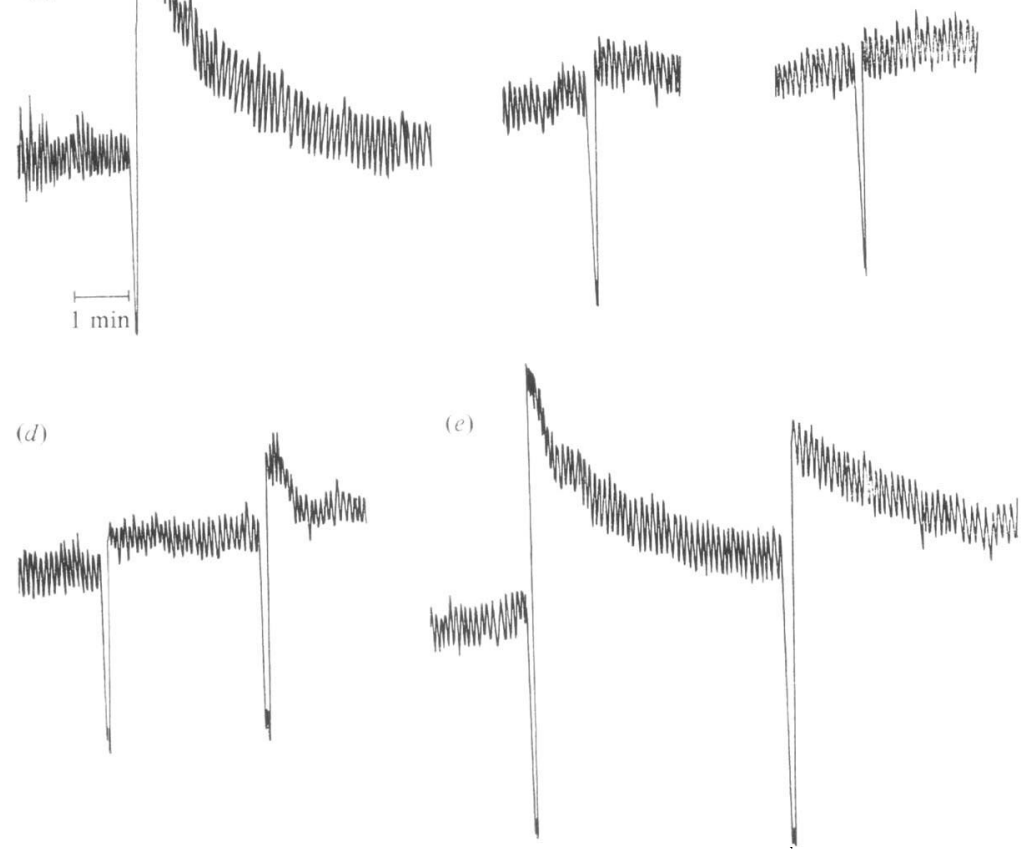

Fig. 2. Effect of uncouplers of oxidative phosphorylation on cyanine dye fluorescence. Bacteria were grown and treated as described in Methods. Reagents were added at times noted by a dip in the tracing to the baseline. One (arbitrary) unit equals the distance of this dip. FCCP and PCP were added from $0 \cdot 1 \mathrm{~mm}$ and $1 \mathrm{~mm}$ stock solutions in $95 \%(\mathrm{v} / \mathrm{v})$ ethanol, respectively. Ethanol itself had no effect on fluorescence. (a) $0.23 \mu \mathrm{M}-\mathrm{FCCP},(b) 0.23 \mu \mathrm{M}-\mathrm{FCCP}$ in cyanine dye medium with KSCN substituted for $\mathrm{KCl},(c) 0.23 \mu \mathrm{M}-\mathrm{FCCP}$ in chemotaxis buffer instead of cyanine dye medium, $(d) 77$ $\mathrm{nM}-\mathrm{FCCP}$ at both times and (e) $0.77 \mu \mathrm{M}-\mathrm{PCP}$ added first and $77 \mathrm{nM}-\mathrm{FCCP}$ added second.

\section{Table 1. Effect of $p H$ on chemotaxis threshold concentrations for repellents}

Threshold concentrations for causing tumbling were determined as described in Methods.

\begin{tabular}{|c|c|c|c|c|}
\hline \multirow[b]{2}{*}{ Repellent } & \multirow[b]{2}{*}{$\mathrm{p} K_{\mathrm{a}}{ }^{*}$} & \multicolumn{3}{|c|}{ Threshold concn (M) } \\
\hline & & pH 6 & pH 7 & pH 8 \\
\hline FCCP & - & $1.0 \times 10^{-9}$ & $1.0 \times 10^{-8}$ & $1.8 \times 10^{-z}$ \\
\hline PCP & $4 \cdot 7$ & $1.0 \times 10^{-8}$ & $1.0 \times 10^{-7}$ & $1.8 \times 10^{-6}$ \\
\hline $3,4,5-\mathrm{TCP}$ & $6 \cdot 2$ & $3 \cdot 2 \times 10^{-7}$ & $3 \cdot 2 \times 10^{-6}$ & ND \\
\hline $3,5-\mathrm{DCP}$ & $7 \cdot 1$ & $1.8 \times 10^{-6}$ & $1.8 \times 10^{-5}$ & ND \\
\hline $2,4,6-\mathrm{TCP}$ & $7 \cdot 5$ & $3.2 \times 10^{-6}$ & $3.2 \times 10^{-5}$ & $3.2 \times 10^{-4}$ \\
\hline Tetracaine & - & $1.9 \times 10^{-4}$ & $1.9 \times 10^{-4}$ & $5.8 \times 10^{-}$ \\
\hline TPB & - & $5.6 \times 10^{-6}$ & $5.6 \times 10^{-6}$ & $3.2 \times 10^{-}$ \\
\hline
\end{tabular}

ND, Not determined because motility became very poor at $5 \cdot 6 \mu \mathrm{M}-3,4,5-\mathrm{TCP}$ and at $56 \mu \mathrm{M}-3,5-\mathrm{DCP}$, concentrations that did not bring about tumbling.

* From Nicholas \& Ordal (1978).

tions. It is apparent from the corrected results that the anion is the active species (Fig. 3). Furthermore, at least for experiments at $\mathrm{pH} 6$ and $\mathrm{pH} 7$, the threshold concentrations are lower at $\mathrm{pH}$ 6. This is probably due to a requirement for protonation of a carboxyl of $\mathrm{p} K$ 5.74 since this group is 6.8 times (the vertical displacement of the two straight lines in Fig. 3 ) more protonated at $\mathrm{pH} 6$ than at $\mathrm{pH} 7$. Probably a different site of interaction with chloro- 


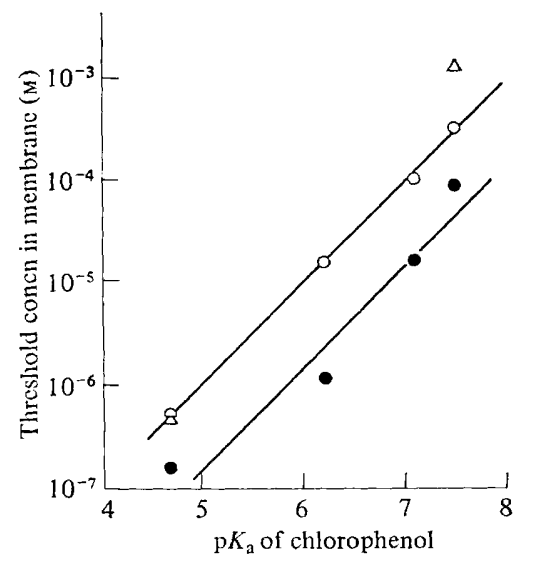

Fig. 3. Correlation between the $\mathrm{p} K_{\mathrm{a}}$ of chloro-substituted phenols and the threshold concentration for causing tumbling. Bacteria were grown and treated as described in Methods. Values of threshold concentrations from Table 1 were divided by partition coefficients $k$ (water/carbon tetrachloride) to obtain values for concentrations within the membrane phase (see text): $0, \mathrm{pH} 6 ; 0, \mathrm{pH} \mathrm{7;}$ $\triangle, \mathrm{pH}$ 8. Straight lines through $\mathrm{pH} 6$ and $\mathrm{pH} 7$ points were drawn assuming that: $\mathrm{d}(\log$ threshold concn) $/ \mathrm{dp} K_{\mathrm{a}}=1$.

phenols is involved in the experiments at $\mathrm{pH} 8$, since the threshold concentrations are much lower than expected (Fig. 3).

Finally, the threshold concentration of strain OI 1100, a chemotaxis mutant whose methylation/demethylation system does not function, was tested for response to FCCP. The threshold was $18 \mathrm{nM}$, the same as for the wild-type parent, OI 1085. Tumbling caused by the addition of $0.32 \mu \mathrm{M}$-FCCP lasted $44 \pm 3 \mathrm{~s}$ in the mutant and $48 \pm 5 \mathrm{~s}$ in the wild-type. Thus, as postulated by Ordal (1976a), methylation/demethylation is not involved in chemotaxis away from membrane-active repellents of $B$. subtilis.

\section{DISCUSSION}

What is the mechanism by which repellents cause a transient period of tumbling in $B$. subtilis? Do changes in membrane potential brought about by the repellent have any influence on behaviour? Do $\mathrm{Ca}^{2+}$ fluxes occur? We will concentrate on the uncouplers of oxidative phosphorylation in discussing these questions.

Uncouplers of oxidative phosphorylation cause depolarization of the plasma membrane, shown directly for B. subtilis by Miller \& Koshland (1977) and confirmed by the present work. However, we have shown a lack of correlation between membrane depolarization and tumbling. Furthermore, Fig. 3 of Miller \& Koshland (1977) shows that behaviour returns to normal long before the depolarization is over. Finally, most uncouplers and other repellents act at specific sites to cause tumbling, whereas uncouplers are not believed to act at specific sites to cause membrane depolarization, but rather diffuse through the membrane as an ion in one direction and as a neutral species in the other (Mitchell, 1966). Therefore, membrane depolarization plays no apparent role in the tumbling caused by uncouplers. Fast transient changes, of several seconds or less, cannot be detected by the methods employed here and might play a role. However, except for this possible qualification, membrane depolarization and tumbling are entirely separate manifestations of interaction of certain reagents with bacteria.

$\mathrm{Ca}^{2+}$ fluxes were considered as a possible means of accounting for repellent activity: $\mathrm{Ca}^{2+}$ would enter the cell during membrane depolarization caused by the repellent, cause tumbling due to its higher cytoplasmic concentration, and then leave following repolarization. However, membrane depolarization is not correlated with repellent activity and, in any case, 
repolarization takes too long. Furthermore, as shown in Fig. 1, large $\mathrm{Ca}^{2+}$ fluxes do not occur. Small ones might (see below), but at present cannot be determined.

How, then, can we understand the mechanism by which uncouplers cause tumbling? The salient property of uncouplers is that they can have multiple effects on cells. Brummett \& Ordal (1977) found that PCP inhibited proline uptake into B. subtilis non-competitively but glycine uptake uncompetitively; TCSA inhibited proline uptake non-competitively but glycine uptake competitively; FCCP inhibited proline uptake uncompetitively but glycine uptake competitively. Nicholas \& Ordal (1978) showed that, at least for PCP and its analogues, the main inhibiting species is the anion, and that the site of inhibition is within the membrane. Similarly, Fig. 3 indicates that the anionic forms of the chloro-substituted phenols are the agents that cause tumbling. PCP, which has the greatest tendency to be ionized, is the most potent repellent; 2,4,6-TCP which has the greatest tendency to be protonated (neutral) is the least potent repellent. The order should have been reversed had the protonated forms been repellents and all chloro-substituted phenols should have been about equally potent were the state of protonation unimportant. Furthermore, the locus of inhibition must lie within the membrane. It cannot be at the cell exterior since PCP is as much better an inhibitor than 2,4,6-TCP at pH 8, where both are mainly anionic, as at $\mathrm{pH} 6$ where only PCP is anionic. Nor can it lie within the cell at the interior surface of the membrane, since at the internal $\mathrm{pH}$ of 7.55 (Navon et al., 1977), 2,4,6-TCP is about half-ionized but is still 180 to 320 times less efficient as a repellent than PCP. Within the membrane, where the dielectric constant is low and accordingly the energy required for ionization is greater, the $\mathrm{p} K$ values of all the chloro-substituted phenols will be shifted to higher values. This shift is fairly large, since at $\mathrm{pH} 7 \mathrm{PCP}$ is 32 times as potent a repellent as 3,4,5-TCP, and the shift in dissociation constant for protonation is also 32 -fold. Were the concentration of anion for each nearly the same, both should have been equally good repellents.

The mechanism of inhibition of amino acid transport by uncouplers was proposed to be binding to transport proteins at specific sites, the free energy of interaction of which stabilizes proteins in particular conformations and thus makes unlikely the conformational changes needed to carry out the function of amino acid transport (Brummett \& Ordal, 1977). Nicholas \& Ordal (1978) proposed that such interactions with membrane proteins are commonplace since, in each of six instances examined (three uncouplers affecting two transport systems), specific inhibition was found.

Likewise, we believe that these uncouplers bind to many proteins in the membrane stabilizing them in certain conformations. Assuming that tumbling frequency is controlled for each bacterium by the concentration of some cytoplasmic ion (such as $\mathrm{Ca}^{2+}$ ), metabolite or protein, it might be that a few of the membrane proteins that face the cytoplasm normally bind this substance but then release it due to a conformational change caused by binding uncoupler. Upon addition of repellent, tumbling ensues and continues until the concentration change (probably an increase) is returned to normal through active transport or metabolism.

It should be emphasized that this mechanism of repellent action does not involve the methylation of methyl-accepting chemotaxis proteins (MCPs) since the threshold for FCCP is normal in a chemotaxis mutant defective in methylation. Nor can the MCPs themselves be the site of interaction of repellents since the sites are different for chemically dissimilar repellents (Ordal, 1976b). Rather, chemotaxis away from noxious membrane-active agents in B. subtilis represents a novel form of chemotaxis in which the plasma membrane itself acts as a generalized antenna for harmful substances in the environment. Detailed understanding of its mechanism will aid our quest to elucidate orthodox (methylation, chemoreceptor-related) chemotaxis. 
We are grateful to Dr A. S. Waggoner for the gift of the cyanine dye and to Dr P. G. Heytler for the gift of FCCP. This work was supported by grant GM21130 and Research Career Development Award GM00160 to George W. Ordal, both from the Institute of General Medical Sciences, N.I.H.

\section{REFERENCES}

AdLER, J. (1969). Chemoreceptors in bacteria. Science 153, 708-716.

Aksamit, R. \& Koshland, D. E., JR (1974). Identification of the ribose-binding protein as the receptor for ribose chemotaxis in Salmonella typhimurium. Biochemistry 13, 4473-4478.

Berg, H. C. \& Brown, D. A. (1972). Chemotaxis in Escherichia coli analyzed by three-dimensional tracking. Nature, London 239, 500-504.

BrummetT, T. B. \& ORDAL, G. W. (1977). Inhibition of amino acid transport in Bacillus subtilis by uncouplers of oxidative phosphorylation. Archives of Biochemistry and Biophysics 178, 368-372.

Hazelbauer, G. L. \& AdLer, J. (1971). Role of the galactose-binding protein in chemotaxis of Escherichia coli toward galactose. Nature New Biology 230, 101-104.

Kort, E. N., Goy, M. F., LARsen, S. H. \& Adler, J. (1975). Methylation of a membrane protein involved in bacterial chemotaxis. Proceedings of the National Academy of Sciences of the United States of America 72, 3939-3943.

Macnab, R. \& Koshland, D. E., JR (1972). The gradient-sensing mechanism in bacterial chemotaxis. Proceedings of the National Academy of Sciences of the United States of America 69, 2509-2512.

Miller, J. B. \& Koshland, D. E., JR (1977). Sensory electrophysiology of bacteria: relationship of the membrane potential to motility and chemotaxis in Bacillus subtilis. Proceedings of the National Academy of Sciences of the United States of America 74, 4752-4756.

Mitchell, P. (1966). Chemiosmotic coupling in oxidative and photosynthetic phosphorylation. Biological Reviews 41, 445-502.

Navon, G., Ogawa, S., Shulman, R. G. \& Yamane, T. (1977). High-resolution ${ }^{31} \mathrm{P}$ nuclear magnetic resonance studies of metabolism in aerobic Escherichia coli. Proceedings of the National Academy of Sciences of the United States of America 74, 888-891.

Nicholas, R. A. \& Ordal, G. W. (1978). Inhibition of bacterial transport by uncouplers of oxidative phosphorylation. Effects of pentachlorophenol and analogues in Bacillus subtilis. Biochemical Journal 176, 639-647.

Ordal, G. W. (1976a). Effect of methionine on chemotaxis by Bacillus subtilis. Journal of Bacteriology 125, 1005-1012.

ORDAL, G. W. (1976 $b$ ). Recognition sites for chemotactic repellents of Bacillus subtilis. Journal of Bacteriology 126, 72-79.

OrdaL, G. W. $(1976 c)$. Control of tumbling in bacterial chemotaxis by divalent cation. Journal of Bacteriology 126, 706-711.

ORDAL, G. W. (1977). Calcium ion regulates chemotactic behavior in bacteria. Nature, London 270, 66-67.

ORdal, G. W. \& Fields, R. B. (1977). A biochemical mechanism for bacterial chemotaxis. Journal of Theoretical Biology 68, 491-500.

Ordal, G. W. \& Goldman, D. J. (1975). Chemotaxis away from uncouplers of oxidative phosphorylation in Bacillus subtilis. Science 189, 802805.

Ordal, G. W. \& Goldman, D. J. (1976). Chemotactic repellents of Bacillus subtilis. Journal of Molecular Biology 100, 103-108.

Ordal, G. W., Villani, D. P., Nicholas, R. A. \& HAMEL, F. G. (1978). Independence of proline chemotaxis and transport in Bacillus subtilis. Journal of Biological Chemistry 253, 4916-4919.

Rosen, B. P. \& MCClees, J. (1974). Active transport of calcium in inverted membrane vesicles of Escherichia coli. Proceedings of the National Academy of Sciences of the United States of America 71, 5042-5046.

Tsang, N., Macnab, R. \& Koshland, D. E., JR (1973). Common mechanism for repellents and attractants in bacterial chemotaxis. Science 181, 60-63.

Tso, W. W. \& ADLER, J. (1974). Negative chemotaxis in Escherichia coli. Journal of Bacteriology 118, 560-576. 